\title{
The Interface Between Degradable Mg and Tissue
}

\author{
REGINE WILLUMEIT-RÖMER $\oplus^{1,2}$ \\ 1.-Division Metallic Biomaterial, Helmholtz-Center Geesthacht, Institute for Materials Research, \\ Max-Planck-Str. 1, 21502 Geesthacht, Germany. 2.-e-mail: regine.willumeit@hzg.de
}

\begin{abstract}
Magnesium $(\mathrm{Mg})$ and its alloys degrade under physiological conditions, which makes them interesting implant materials, especially for osteosynthesis and cardiovascular applications. However, how strong is the connection between the implant, the degradation layer, and the surrounding tissue, namely bone? Considering that microscopically the interface can be separated into the border between the metal and the degradation layer, the degradation layer itself, and the border between the degradation layer and the biological environment, it is not obvious that this zone with total thickness of several tens of microns is sufficient to keep an implant in place. However, biomechanical approaches such as push-out tests have shown that a degraded Mg pin is surprisingly well connected with the bone irrespective of the fragile appearance of the degradation layer. This paper provides an overview of what is known about the interface between degrading $\mathrm{Mg}$ implants, cells, and bone tissue.
\end{abstract}

\section{INTRODUCTION}

Tailoring the optimal interaction of implants with tissue in a living organism was and still is a challenge. For permanent implants, it is desirable to establish a durable and life-long connection between the implant and tissue, irrespective of the changes in the tissue upon aging and infections or general changes in the health status of the patient. For degrading implants, application-specific degradation is required to enable the body to regenerate appropriately. The degradation products either should be removed from the body, or (if integrated into the tissue) should not cause any harm throughout the lifetime of the patient.

Considering in particular metallic implants, which are mainly applied for procedures related to hard tissue in trauma and orthopedic surgery, the mechanical load is high in comparison with the size of the implant and stability has to be guaranteed over a longer period. While, e.g., joint implants are supposed to remain in the patient for decades, in many cases, screws, plates, nails, or other implants are removed after healing. This is especially true for children, because permanent implants would compromise their growth. Therefore, degradable metals such as iron, zinc, and magnesium are attractive. However, the requirements on these are the same as for permanent implants, viz. very good connection between the implant and tissue, very good mechanical properties, and very good biocompatibility plus degradability.

With a permanent metallic implant, hydrophilic, hydrophobic, and electrostatic interactions take place within the first nanoseconds after its contact with blood. ${ }^{1}$ This usually results in a nanometerthick oxide layer on the implant surface (for a review see, e.g., Ref. 2). Small ions and water molecules will attach to and detach from the surface, followed by larger salt ions. The next step is adhesion of organic molecules such as amino acids, peptides, and eventually proteins. ${ }^{3,4}$ The ions can also interact with these organic compounds., Eventually, a protective layer is formed on the metal, forming the basis for cells to start to settle on the surface. This can be the expected type of cells, e.g., bone cells, stem cells, etc. These then proliferate and differentiate into the required tissue. ${ }^{7,8}$ However, it can also occur that the surface becomes occupied by unwanted cells such as those generating scar tissue or even bacteria, which will form a biofilm. ${ }^{9,10}$ In all cases, a stable surface (neglecting for the moment the possibility of ion release from metals such as titanium or steel) where the abovementioned processes can take place is present.

In the case of degradable metal implants such as those made from $\mathrm{Mg}$, the situation is different (Fig. 1). Upon interaction with blood, the 


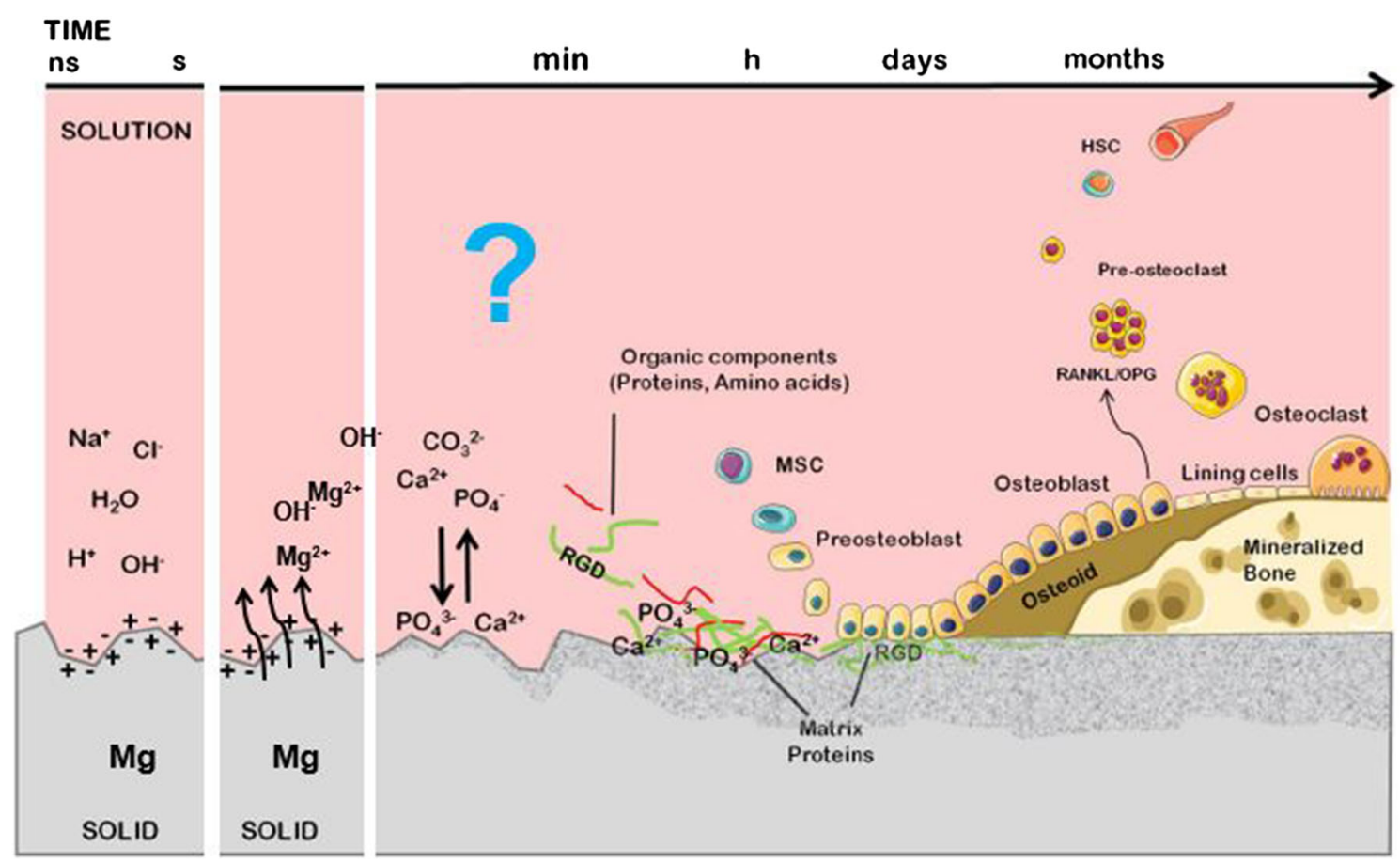

Fig. 1. Schematic of processes occurring after implantation of Mg-based materials, ${ }^{2}$ modified with permission from InTech's Publishing Ethics and Legal Affairs Department. The degradation layer which replaces the oxide layer that usually forms on nondegradable metals (thin dark-grey line) is represented by the irregular greyish color.

electrostatic interaction of the ions and their contact with water take place. In parallel, the degradation process starts. ${ }^{11}$ This influences the subsequent processes, because changes in the $\mathrm{pH}$ and high concentrations of $\mathrm{Mg}$ ions will interfere chemically with the salt ions and organic molecules. Degradation products are also formed and may react with blood compounds, precipitate, or be redissolved, depending on the local conditions. This leads to a relatively thick (several micron) degradation layer, which does not exist for permanent implants. The degradation products may also interact with the biological environment. Cells can metabolize $\mathrm{Mg}$ or the degradation products, in turn changing the availability of these compounds for chemical reactions in the degradation process itself. This again changes the degradation layer between the bulk metal and tissue. In other words, the system is highly dynamic. However, high mechanical stability between the metal and degradation layer and within the degradation layer, as well as very good contact between the implant and tissue, are still required. But what is known about this interface?

In general, nothing quantitative is known about the bonding strength between the metal and degradation layer. To measure the degradation rate, the degradation layer is removed chemically by, e.g., chromic acid treatment. ${ }^{12}$ Some papers describe that a superficial layer of loosely attached degradation products can be removed by a peeling test. ${ }^{13}$ The formation of the degradation layer can be studied under various conditions in vitro without and with cells. ${ }^{14-19}$ However, this provides only an imperfect impression of what will be found after implantation of a degrading $\mathrm{Mg}$ implant into the body. The central problem of how to obtain high-resolution structural, mechanical, and chemical data in vivo while the layer is formed and remodeled until the implant finally disappears persists. Magnetic resonance tomography (MRI) or other imaging technologies such as fluorescence, positron emission tomography (PET), and ultrasound can be used to visualize the implant with low resolution, ${ }^{20,21}$ but are currently not available to study physiological changes around metallic implants in humans. Using x-rays, clinical computer tomography (CT) achieves resolution of a few hundred microns only, ${ }^{22,23}$ which cannot resolve the degradation layer thickness of some $10 \mu \mathrm{m}$. In principle, animal CT can assess layer thicknesses down to $10 \mu \mathrm{m},{ }^{24,25}$ although the relatively low contrast between bone, degradation layer, and bulk metal makes it very difficult to judge exactly where the degradation layer is. If the layer is thinner than $10 \mu \mathrm{m}$, animal $\mu \mathrm{CT}$ can only provide an idea about the general loss of material but no further information. ${ }^{26}$ For ex vivo analysis, use of high-resolution synchrotron tomography enables study of the interface between bone and implant with submicron resolution (as shown by the example in Fig. 2). The contrast between the material, degradation layer, and newly mineralized bone is usually very good, but unambiguous registration and segmentation of the phases can only be achieved when additional information, e.g., from histology, is available. ${ }^{27}$ 


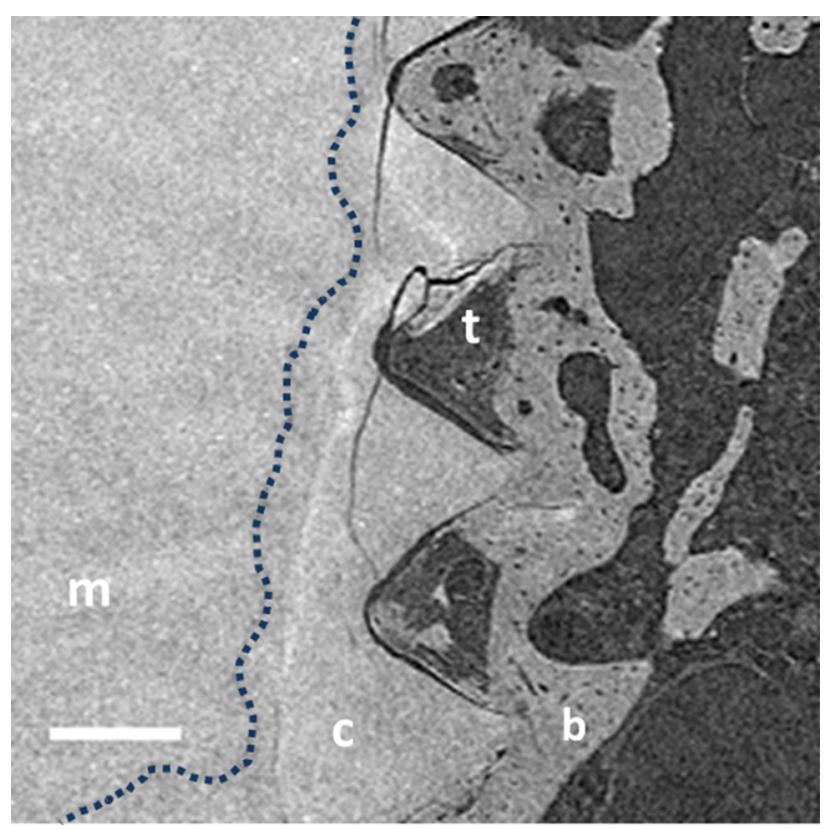

Fig. 2. High-resolution x-ray CT of a Mg-10Gd screw in rat bone at 12 weeks after implantation. Scale bar $200 \mu \mathrm{m}$. The degradation layer (c) is visible along the side of the bulk material $(\mathrm{m})$, with variable greyscales indicating different compositions of the degradation layer. The border between the degradation layer and bulk material is marked by the dotted line. Bone has grown along the threads and can be distinguished into mineralized tissue (b) and nonmineralized tissue (t). Image obtained at the P05 end station of Petra III, DESY (courtesy of Dr. Berit Zeller-Plumhoff, HZG).

In situ and in vivo sensors to monitor the changes in parameters such as $\mathrm{pH}$, temperature, $\mathrm{O}_{2}$ concentration, etc. in the vicinity of a degrading $\mathrm{Mg}$ implant are currently not available. These parameters could be used to model the degradation process and the formation of the interface in vivo, providing indirect information about the degradation layer. The release of $\mathrm{H}_{2}$ can be monitored optically or electrochemically from outside of the body ${ }^{28,29}$ if the implant is placed subcutaneously. These measurements allow noninvasive quantification of $\mathrm{H}_{2}$ but not permanent monitoring of its evolution. A recent paper reported implantation of a $\mathrm{H}_{2}$ sensor that enabled monitoring of gas evolution in bone marrow. ${ }^{30}$ However, this approach is complicated and invasive, and further research is needed to implement this technique for monitoring implant degradation in vivo.

Besides visualization of the degradation layer, knowledge about its mechanical properties would be helpful. For this, indentation ${ }^{31}$ or pull/push-out tests are typically employed. Besides the problems of difficult sample preparation and relatively imprecise measurements generally faced for brittle materials, a further difficulty with indentation measurements of the bone-Mg implant interface is how to prepare the interface without removing parts of the degradation layer and thus changing its properties; For example, to study bone samples, the bone is fixed in resin and rehydrated after grinding and polishing, e.g., for $40 \mathrm{~h}$ in Hank's balanced salt solution (HBSS). ${ }^{32}$ This would certainly lead to degradation of the specimen if a bone-Mg implant cross-cut were to be investigated. In addition, indentation usually measures areas with dimension of about $50-100 \mu \mathrm{m}$, which is larger than the degradation layer. Further aspects influencing measurements of biological specimens such as bone include the following: ${ }^{33}$ (i) The small mass of the specimen increases the error; It is recommended to have a sample of at least $10 \mathrm{~g}$, which is hardly achievable when dealing with an implant in a mouse or rat bone; (ii) Measurements too close to a pore/channel in the bony structure; For microindentation, the minimum distance between the center of the indentation and the edge of a pore should be larger than $73 \mu \mathrm{m}$.

Nanoindentation faces the same problems in terms of sample preparation but delivers very appropriate deformation areas. ${ }^{34}$ Still, this kind of measurement is hardly applicable to degradable Mg-based implants.

A rough estimate of the mechanical properties can be made by assuming that the composition of the degradation layer is similar to that of hydroxyapatite, as the mechanical properties for typical calcium phosphates such as tricalcium phosphate [TCP, $\left.\mathrm{Ca}_{3}\left(\mathrm{PO}_{4}\right)_{2}\right]$ and hydroxyapatite [HA, $\left.\mathrm{Ca}_{10}\left(\mathrm{PO}_{4}\right)_{6}(\mathrm{OH})_{2}\right]$ are known. For HA, the ultimate compressive strength (UCS) ranges from 500 to $1000 \mathrm{MPa}$, the tensile strength does not exceed $50 \mathrm{MPa}$, and the elastic modulus is approximately 80-117 GPa. ${ }^{35,36}$ The Vickers hardness was reported to be $600 \mathrm{HV}^{37}$ In particular, the low ultimate tensile strength (UTS) together with a low fracture toughness $(0.6-1 \mathrm{MPa} / \mathrm{m})^{38}$ give relative poor mechanical properties under tension. In comparison, for cortical bone, mechanical parameters of UCS of $100-230 \mathrm{MPa},{ }^{36}$ UTS of $50-151 \mathrm{MPa},{ }^{39}$ elastic modulus of 7-30 GPa, and fracture toughness of 2-12 $\mathrm{MPa} \mathrm{m}^{1 / 2}$ can be found. ${ }^{38}$ The mechanical properties of magnesium and its alloys, on the other hand, can, in some cases, reach well beyond those of calcium phosphates, with UCS of 45$100 \mathrm{MPa}$, UTS of 135-285 MPa, elastic modulus of 41-45 GPa, and fracture toughness of 15$40 \mathrm{MPa} \mathrm{m}{ }^{1 / 2}$. ${ }^{0}$ Therefore, one can expect that, under tension, the degradation layer will be the weakest zone. However, no information about the bonding strength between the metal and degradation layer or for the interface between the degradation layer and bone tissue is available.

\section{In Vitro Studies of the Degradation Layer}

\section{Cell-Free Situation}

Obviously, the majority of degradation studies are performed without cells, and still quite often under purely technical conditions. The validity of these results for the situation in vivo is a matter of debate. In cases where physiological conditions are 

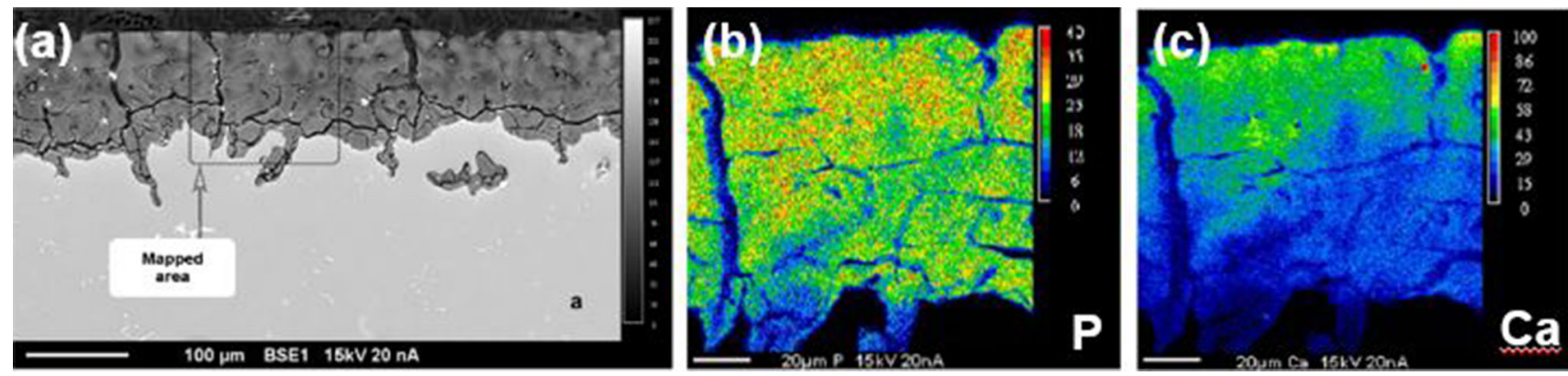

Fig. 3. Structure and elemental composition of a AM60B-F specimen tested for $168 \mathrm{~h}$ using shear stress of $4.4 \mathrm{~Pa}$ in modified Hank's solution ${ }^{41}$ (modified with permission from Elsevier): (a) backscattered electron SEM image, and $x$-ray maps of (b) $P$ and (c) Ca in the area indicated on the cross-section in (a).

mimicked at least partially (temperature $37^{\circ} \mathrm{C}$, degradation medium simulating body fluid or cell culture medium, presence of $\mathrm{CO}_{2}$, control of $\mathrm{O}_{2}$, and degradation under flow conditions, to name just a few), the predictability of the degradation rate in vivo is much better. However, the number of studies analyzing in depth what is formed on the surface under different conditions is rather limited. Even fewer papers have been published on the internal composition and the structure of the layer, although some very good examples of in-depth analysis of the degradation layer can be found, e.g., for the case of cardiovascular applications of Mg. Although a more technical alloy was used in a setup inducing shear stress, a clear inhomogeneous distribution of detected chemical elements $\mathrm{Ca}$ and $\mathrm{P}$ are given as examples) can be seen (Fig. 3). ${ }^{41}$ Another study showed exemplarily the structure of the layer and how it exfoliates from the bulk. ${ }^{42} \mathrm{~A}$ general overview on the progress of degradation can be found in Ref. 43.

The principal reaction during $\mathrm{Mg}$ degradation is rather simple and should lead to the formation of a $\mathrm{MgO}$ or $\mathrm{Mg}(\mathrm{OH})_{2}$ layer in a highly alkaline environment. However, under near-physiological conditions, the situation is different. ${ }^{44} \mathrm{As}$ mentioned above, first, various salts and organic compounds (amino acids, proteins, lipids, carbohydrates, etc.) are present. These can accelerate the degradation or slow it down and thus influence the composition of the degradation layer. Inorganic salts such as $\mathrm{MgSO}_{4}$ or $\mathrm{NaHCO}_{3}$ in general seem not to have such a severe effect on the degradation rate and layer composition as organic molecules do. However, the latter in particular, in combination with $\mathrm{CaCl}_{2}$, results in an increase in $\mathrm{MgCO}_{3}$ and $\mathrm{Ca}-\mathrm{PO}_{4}$ formation, causing a decrease in the degradation rate. ${ }^{45}$ The role of $\mathrm{Ca}$ in different solutions is varying: in $\mathrm{NaCl}$ it does not have an effect, whereas under more physiological conditions it can also accelerate the degradation. ${ }^{46}$ The important role of $\mathrm{Ca}$ in physiological solutions was also proven by attenuated total reflectance (ATR) Fourier-transform infrared (FTIR) spectroscopy measurements, which suggested that $\mathrm{Ca}^{2+}$ stimulates rapid precipitation of hydroxyapatite at the interface. ${ }^{47}$
Together with $\mathrm{P}$, which is always present under physiological conditions, this can induce rapid nucleation and growth of noncrystalline Ca-P precipitates, a precursor of inorganic bone matrix.

While small organic compounds in general can increase the layer thickness, a particular composition of amino acids and proteins can also decrease the layer thickness. ${ }^{13}$ These compounds (Fig. 4) determine which final $\mathrm{Mg}$ complex is predominantly formed at the surface. When one organic component (amino acids: aspartic acid, glutamine, or alanine) was added to the degradation medium, the dominant forms of $\mathrm{Mg}$ compounds were hydromagnesite $\left[\mathrm{Mg}_{5}\left(\mathrm{CO}_{3}\right)_{4}(\mathrm{OH})_{2} \cdot 4 \mathrm{H}_{2} \mathrm{O}\right]$ and giorgiosite $\left[\mathrm{Mg}_{5}\left(\mathrm{CO}_{3}\right)_{4}(\mathrm{OH})_{2} \cdot 5\left(\mathrm{H}_{2} \mathrm{O}\right)\right]$ according to x-ray diffraction (XRD) analysis (refer to the original paper). If two organic components were added, nesquehonite $\left[\mathrm{MgCO}_{3} \cdot 3 \mathrm{H}_{2} \mathrm{O}\right]$ was the dominant precipitate. Addition of three organic components also led to formation of nesquehonite as the dominant precipitate. All immersion experiments were performed under cell culture conditions (95\% humidity, $21 \% \mathrm{O}_{2}, 5 \%$ $\mathrm{CO}_{2}, 37^{\circ} \mathrm{C}$ ). Strikingly, it did not seem to matter which organic compound was added, but only how they were combined. During degradation, the osmolality increased, as indicated by the deeper color of the medium. The degradation layer was not homogeneous: at least two regions with different compositions could be identified, as demonstrated in Fig. 3, an effect that became even more pronounced when small organic compounds were present.

While the question of whether proteins promote or reduce the degradation rate is still subject to discussion in literature, there is consensus that proteins affect the degradation rate and determine the formation of degradation products. ${ }^{48,49}$ Proteins can build chelate complexes which can increase the dissolution rate of $\mathrm{Mg}(\mathrm{OH})_{2} \cdot{ }^{47}$ In the same work, it was shown by Fourier-transform infrared (FTIR) spectroscopy that proteins have a significant impact on the formation of passivating calcium phosphate layers, which is inhibited in the presence of proteins. Closer inspection of the composition and morphology of the degradation layer revealed that the layer could be significantly thicker and less dense when proteins are present. In addition, the 


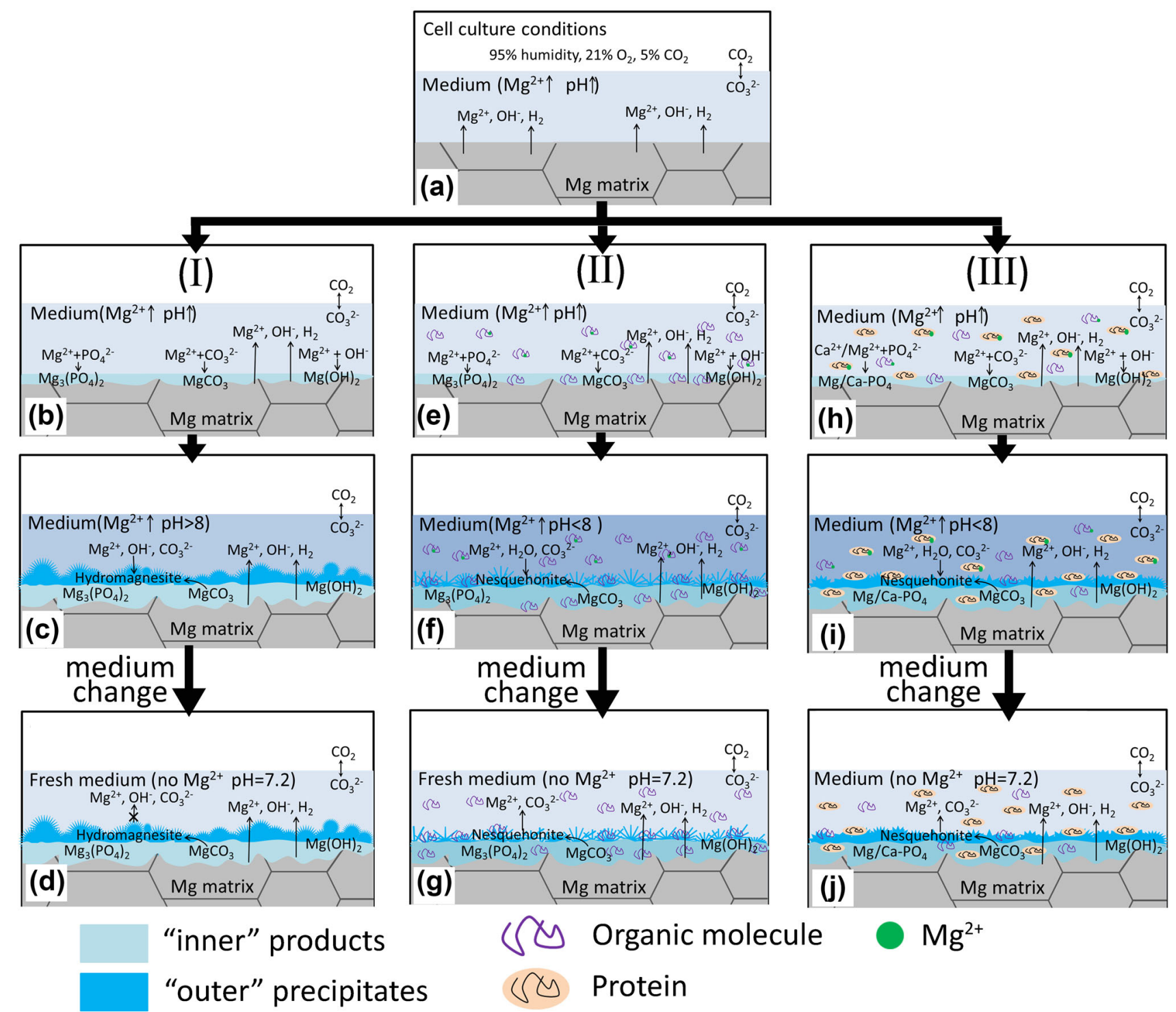

Fig. 4. Schematic of degradation of pure Mg in different media. (from Ref. 13 with permission from Springer). Starting from pure Mg (a), different morphologies and layer compositions can be achieved on addition of (b-d) HBSS or HBSS with one organic component (amino acids: aspartic acid, glutamine, or alanine), (e-g) HBSS with two organic components, and (h-j) HBSS with three organic components. Two layers are formed (light and darker blue color, where darker blue indicates higher content of phosphate).

two regions with different composition, as mentioned for small organic molecules, become more visible when proteins are added to the immersion medium. $\mathrm{Ca}$ and $\mathrm{P}$ are mainly found in the deeper regions of the layer, closer to the bulk material, and less at the surface. 50

\section{Degradation in Presence of Cells}

Beside small molecules and proteins, obviously cells also come into contact with the degrading material. In vitro studies have shown that an intact cell layer can form a protection layer which can reduce the degradation rate of the material. ${ }^{51}$ In addition, the cells can alter the composition of the degradation layer, as was shown for fibroblasts. ${ }^{51}$ This becomes quite important when the formation of the degradation layer underneath the bone-forming cells, the osteoblasts, is studied. Focused ion beam (FIB) milling and analysis of the cross-sections of the degradation layer by energy-dispersive $\mathrm{x}$-ray (EDX) spectroscopy line scans ${ }^{52}$ showed that the thickness as well as the composition of the layer are altered. It can be speculated that osteoblasts actively remodel the degradation layer by their metabolic activity. This of course could have consequences for the layer properties and the bone formation.

To the best of our knowledge, osteoclasts and their influence on the degradation and degradation layer composition have not yet been studied. Since osteoclasts form lacuna in which the $\mathrm{pH}$ is lowered to around 4.5 , severe degradation can be expected. ${ }^{53}$ 
However, investigation of this aspect is challenging, since no cells can survive on a fast degrading $\mathrm{Mg}$ based material. In addition, osteoclasts are quite sensitive to elevated $\mathrm{Mg}$ concentrations, ${ }^{54}$ and can only tolerate higher levels up to $25 \mathrm{mM}$ when osteoblasts are present. ${ }^{55}$

There are no systematic studies about the effect of bacteria on the degradation of $\mathrm{Mg}$ or the composition of the degradation layer. This is partially caused by the antimicrobial effect of fast degrading $\mathrm{Mg}$ alloys ${ }^{56}$ or because $\mathrm{Ag}$ or $\mathrm{Zn}$ were used as alloying elements. ${ }^{57,58}$ On the other hand, it is reported that, on slowly degrading $\mathrm{Mg}$-based materials, bacteria can survive very well, ${ }^{59}$ although the degradation layer is then so thin that its analysis is challenging.

Some studies (e.g., Refs. 60, 61 and 62) have investigated degradation under load, and it can be expected that this external parameter will also influence the properties of the degradation layer. However, there are no systematic studies on the mechanical properties of the degradation layer. It appears very fluffy and brittle ${ }^{60,63}$ and it has been reported several times that part of the very thin degradation layer can exfoliate. ${ }^{64}$ However, some of the cracks visible in microscopic images may only be drying artefacts.

In summary, all environmental factors applied in vitro show effects on the degradation rate and the morphology and composition of the layer.

\section{In Vivo Studies of the Degradation Layer Be- tween Material and Bone}

To date, no techniques to deliver longitudinal information about the development of the degradation layer and its properties in situ and in vivo are available. With high-resolution animal CT, to a certain extent, how fast the material degrades can be monitored, but the resolution is too poor to enable any qualitative statements to be made about the degradation layer. Therefore, ex vivo methods have to be applied to provide insights into the structure and composition of the degradation layer, and to some extent its mechanical properties. Their resolution in space and composition is usually high, but the drawback is that only one specimen per time point is available. The usual methodologies of ex vivo analysis are histology and characterization by spectroscopy or microscopy (e.g., Ref. 57).

Whenever material is explanted, it is observed that a very brittle surface has formed. ${ }^{65}$ In those cases where the material is implanted as, e.g., an extraluminal tracheal stent, direct access to this surface and detailed analysis are possible ${ }^{66}$ revealing the known precipitates of $\mathrm{Ca}-\mathrm{P}$ on the surface and the accumulation of alloying elements near the surface. Despite the variety of experimental setups, implant geometries, sites, as well as analytical methods applied, there seems to be a consensus that mainly Ca-P or even hydroxyapatite forms in the degradation layer in vivo also. ${ }^{67}$
In vivo observation of the interface is always complicated, since preparation of histological sections while keeping the implant in place is quite complex. Still, when this preparation succeeds, it is clearly visible that the interface changes over time and adopts an increasingly bone-like structure. ${ }^{68}$ Even details of the degradation layer can be visualized (Fig. 5). ${ }^{69}$

The variability of the degradation layer thickness is quite large: In Fig. 5, the degradation layer is about $30 \mu \mathrm{m}$ thick. Other publications report calcified zones up to $100 \mu \mathrm{m}$ from the implant surface, or no degradation layer at all. ${ }^{70}$

A relatively new approach is the investigation of implant failure by ex vivo and in situ synchrotron tomography. With this technique, a push-out device is installed in the synchrotron beam. The sample is mounted in a three-dimensionally (3D) printed individualized sample holder. While the tomogram is taken, the load applied to the sample must be kept constant in order to guarantee perfect tomographical data. These data, acquired with resolution of approximately $1 \mu \mathrm{m}$ or even submicron, show that the contact between the bone and implant is so strong and stable that cracks appear only between the corroded surface of the implant and the bone, or in the bone tissue itself. ${ }^{71,72}$ This is quite surprising because, if we assume that the degradation layer consists of a hydroxyapatite (HA)-like inorganic matrix, the cracks should occur in the layer, since the fracture toughness of HA is about 10 times lower than that of $\mathrm{Mg}$.

The interface between the implant and tissue (e.g., bone) consists not only of the degradation layer but also of a newly formed organic/inorganic biological matrix. How does this part of the interface look? Is the bone quality and bone-implant contact as good as we know from, for instance, titanium implants? Scanning synchrotron x-ray scattering (SAXS) can provide an answer to this question. ${ }^{73}$ In the case where the implant is set transcortical in bone, as expected, no load-dependent orientation of the bone crystallites is seen. Instead, the crystallites orient preferably parallel to the implant surface, which might be caused directly by the formation of HA crystallites during the degradation process.

Experiments on $\mathrm{Mg}$ pins inserted into avital bones show that degradation leads to an increased pull-out force, suggesting that the expanding degradation layer interlocks with the surrounding bone. ${ }^{74}$ Push-out tests on titanium, polymer, and magnesium explants show a very strong connection between the material and surrounding bone, despite the fact that the surface of $\mathrm{Mg}$ appears very brittle. In fact, after 6 months in the animal, the Mg pins needed approximately four times more load to be pushed out than a polymer pin; in comparison with titanium pins, more than two times the load was needed. Similar observations were made with pullout tests: The extraction torque of coated AZ31B increased with implantation time, and was higher 
(a)

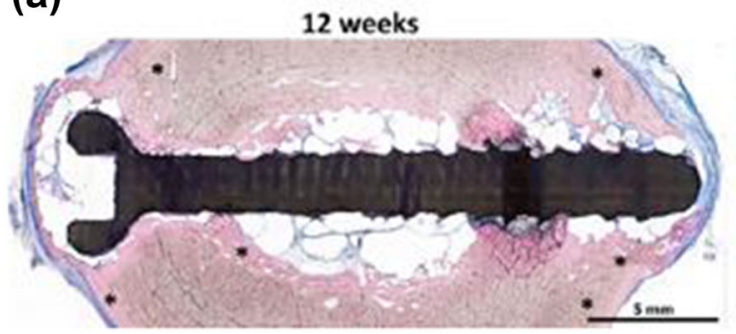

(b)

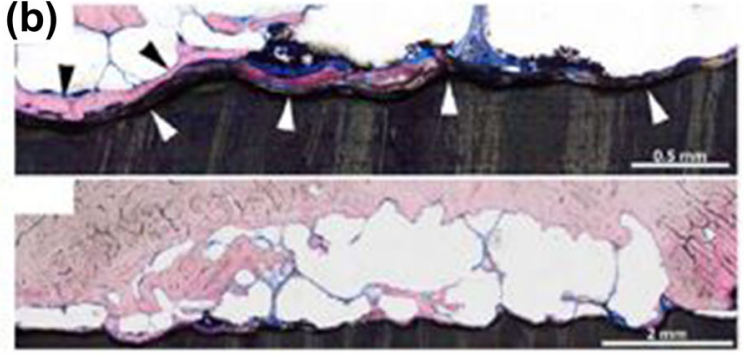

Fig. 5. Histological section of a ZX00 screw implanted for 12 weeks in a sheep bone ${ }^{69}$ (with permission from Elsevier): (a) histological overview of the screw and surrounding tissue, and (b) two closeups. The upper image nicely shows the contact area between bone (black arrows) and material, in particular the degradation layer (white arrows), which is only a few microns thick. The lower image shows an area with gas formation (white bubbles).

than that of poly-L-lactide (PLLA) after 4 weeks of implantation, equaling that of Ti6Al4V at 12 weeks and higher at 21 weeks. ${ }^{75}$

Measuring the mechanical properties of ex vivo specimens is, as mentioned above, quite difficult. However, for the fixation of a tendon graft with a $\mathrm{Mg}$ screw, it was shown that $\mathrm{Mg}$ induced faster mineralization than a $\mathrm{Ti}$ screw, leading to hardness of 28-31 HV, comparable to that of bone tissue. ${ }^{26}$ Nanoindentation was applied to compare the hardness of the bone around degraded WZ21 and ZX50 alloys at different time points postimplantation. ${ }^{76}$ These measurements revealed a slight decrease of hardness at the interface, which the authors interpreted as immature bone.

It is assumed that the degradation layer, or rather the degradation products, stay at the interface between the bulk material and (newly formed) tissue until the implant is degraded completely and the tissue remodeled. However, with laser ablation inductively coupled plasma mass spectrometry (LAICP-MS) measurements, it is possible to visualize the increase in $\mathrm{Mg}$ concentration ${ }^{77}$ and alloying elements up to $2 \mathrm{~mm}$ around the implant while the implant is degrading. ${ }^{78}$ This distance is much greater than the thickness of the degradation layer. Where the alloying elements are found is element specific. Yttrium, for example, was found to migrate further into the bone over time and to remain in the tissue even after complete degradation of the implant. ${ }^{78}$

\section{CONCLUSION}

Use of magnesium as an implant material is still a wide field of research. It has been shown that the presence of inorganic and organic molecules can change the degradation process and the formation and composition of the degradation layer. In addition, it has become clear that these processes also vary with time. The dynamic biological environment, which is usually not considered for nondegradable metal implants, also plays a major role in the process of how the material is eventually resorbed or even metabolized by the organism. When the degradation of the material is aligned to the capacity of the tissue to deal with moderate $\mathrm{pH}$ changes and gas evolution, the connection between the implant and tissue is excellent. However, this knowledge also reveals that we are just starting to understand the interaction between Mg-based implants and the surrounding tissue. In particular, effort is needed for longitudinal and multimodal characterization of in vivo implant degradation with regard to possible human applications: to develop, on the one hand, (implantable or noninvasive) miniaturized sensors to measure chemical and biological parameters at the site of implantation, and on the other hand, imaging technologies to visualize the geometry and degradation layer of the implant and the structure of the surrounding tissue, as well as physiological changes at higher resolution. In addition, computational medicine or engineering must be developed using scale-bridging models for material production and processing as well as the various chemical and biological interactions. The more that details become measurable using improved methodologies and techniques and can be modeled using computational approaches, the better will be the understanding of the system and the means to tailor materials according to the needs of the tissue. There is great potential for $\mathrm{Mg}$ implants, which have a very good chance to become an established clinical treatment.

\section{ACKNOWLEDGEMENTS}

I wish to thank my coworkers Björn Wiese, Norbert Hort, and especially Katharina Philipp for their support. In addition, I am very grateful for the provision of Fig. 2 by my coworker Berit ZellerPlumhoff.

\section{OPEN ACCESS}

This article is distributed under the terms of the Creative Commons Attribution 4.0 International License (http://creativecommons.org/licenses/by/4.0/), which permits unrestricted use, distribution, and reproduction in any medium, provided you give appropriate credit to the original author(s) and the source, provide a link to the Creative Commons license, and indicate if changes were made. 


\section{REFERENCES}

1. P. Roach, D. Eglin, K. Rohde, and C.C. Perry, J. Mater. Sci. Mater. Med. 18, 1263 (2007).

2. A. Shchukarev, M. Ransjö, and Z.I. Mladenović, To build or not to build: the interface of bone graft substitute materials in biological media from the view point of the cells. Biomaterials Science and Engineering, ed. P.R. Pignatello (InTech: Rijeka, 2011), p. 287.

3. A. Bruinink, M. Bitar, M. Pleskova, P. Wick, H.F. Krug, and K. Maniura-Weber, J. Biomed. Mater. Res. Part A 102, 275 (2014).

4. A.H. Morris and T.R. Kyriakides, Matrix Biol. 37, 183 (2014).

5. A. Hoppe, N.S. Güldal, and A.R. Boccaccini, Biomaterials 32, 2757 (2011).

6. G. Jell and M.M. Stevens, J. Mater. Sci. Mater. Med. 17, 997 (2006)

7. L.J. Raggatt and N.C. Partridge, J. Biol. Chem. R109, 041087 (2010)

8. H. Terheyden, N.P. Lang, S. Bierbaum, and B. Stadlinger, Clin. Oral Implants Res. 23, 1127 (2012).

9. C.R. Arciola, D. Campoccia, and L. Montanaro, Nat. Rev. Microbiol. 16, 397 (2018).

10. S. Veerachamy, T. Yarlagadda, G. Manivasagam, and P.K. Yarlagadda, Proc. Inst. Mech. Eng. Part H 228, 1083 (2014).

11. S. Agarwal, J. Curtin, B. Duffy, and S. Jaiswal, Mater. Sci. Eng. C 68, 948 (2016).

12. A. Atrens, G. Song, Z. Shi, A. Soltan, S. Johnston and M. Dargusch, Reference Module in Chemistry, Molecular Sciences and Chemical Engineering. http://doi.org/10.1016/B9 78-0-12-409547-2.13426-2 (2017).

13. R.-Q. Hou, N. Scharnagl, F. Feyerabend, and R. WillumeitRömer, Corr. Sci. 132, 35 (2018).

14. X. Gu, Y. Zheng, S. Zhong, T. Xi, J. Wang, and W. Wang, Biomaterials 31, 1093 (2010).

15. N. Kirkland, J. Lespagnol, N. Birbilis, and M. Staiger, Corr. Sci. 52, 287 (2010).

16. A.H.M. Sanchez, B.J. Luthringer, F. Feyerabend, and R. Willumeit, Acta Biomater. 13, 16 (2015).

17. G. Wu, Y. Zhao, X. Zhang, J.M. Ibrahim, and P.K. Chu, Corr. Sci. 68, 279 (2013).

18. Y. Xin and P.K. Chu, Mater. Chem. Phys. 124, 33 (2010).

19. A. Yamamoto and S. Hiromoto, Mater. Sci. Eng. C 29, 1559 (2009).

20. A. Gigante, N. Setaro, M. Rotini, S. Finzi, and M. Marinelli, Injury 49, S48 (2018).

21. L. Sonnow, S. Könneker, P.M. Vogt, F. Wacker, C. Falck, and B.M.C. Med, Imaging 17, 16 (2017).

22. O. Kose, A. Turan, M. Unal, B. Acar, and F. Guler, Arch. Orthop., Mechanother. Unfallchir. 1, 1069 (2018).

23. D. Zhao, F. Witte, F. Lu, J. Wang, J. Li, and L. Qin, Biomaterials 112, 287 (2017).

24. J. Levorova, J. Duskova, M. Drahos, R. Vrbova, D. Vojtech, J. Kubasek, M. Bartos, L. Dugova, D. Ulmann, and R. Foltan, J. Biomater. Appl. 32, 886 (2018).

25. H. Waizy, J. Diekmann, A. Weizbauer, J. Reifenrath, I. Bartsch, V. Neubert, R. Schavan, and H. Windhagen, J. Biomater. Appl. 28, 667 (2014).

26. J. Wang, J. Xu, B. Song, D.H. Chow, P.S.-H. Yung, and L. Qin, Acta Biomater. 63, 393 (2017).

27. L. Xu, G. Yu, E. Zhang, F. Pan, and K. Yang, J. Biomed. Mater. Res. 83A, 703 (2007).

28. D. Zhao, T. Wang, J. Kuhlmann, Z. Dong, S. Chen, M. Joshi, P. Salunke, V.N. Shanov, D. Hong, and P.N. Kumta, Acta Biomater. 36, 361 (2016)

29. D. Zhao, T. Wang, W. Hoagland, D. Benson, Z. Dong, S. Chen, D.-T. Chou, D. Hong, J. Wu, and P.N. Kumta, Acta Biomater. 45, 399 (2016).

30. D. Zhao, A. Brown, T. Wang, S. Yoshizawa, C. Sfeir, and W.R. Heineman, Acta Biomater. 73, 559 (2018).

31. Y. Bala, B. Depalle, T. Douillard, S. Meille, P. Clément, H. Follet, J. Chevalier, and G. Boivin, J. Mech. Behav. Biomed. Mater. 4, 1473 (2011).
32. J. Kruzic, D. Kim, K. Koester, and R. Ritchie, J. Mech. Behav. Biomed. Mater. 2, 384 (2009).

33. W.M. Johnson and A.J. Rapoff, J. Mater. Sci. Mater. Med. 18, 591 (2007).

34. S. Naderi, M. Hassan, and A. Bushroa, Mater. Des. 67, 360 (2015).

35. K.S. Katti, Coll. Surf. B Biointerfaces 39, 133 (2004).

36. T. Kokubo, H.-M. Kim, and M. Kawashita, Biomaterials 24 2161 (2003)

37. L. Hench, J. Am. Ceram. Soc. 81, 1705 (1998).

38. M. Amaral, M. Lopes, R. Silva, and J. Santos, Biomaterials 23, 857 (2002).

39. Q. Chen, C. Zhu, and G.A. Thouas, Prog. Biomater. 1, 2 (2012).

40. K. Kuśnierczyk and M. Basista, J. Biomater. Appl. 31, 878 (2017).

41. J. Lévesque, H. Hermawan, D. Dubé, and D. Mantovani, Acta Biomater. 4, 284 (2008).

42. W. Wu, S. Chen, D. Gastaldi, L. Petrini, D. Mantovani, K. Yang, L. Tan, and F. Migliavacca, Acta Biomater. 9, 8730 (2013).

43. X. Li, X. Liu, S. Wu, K. Yeung, Y. Zheng, and P.K. Chu, Acta Biomater. 45, 2 (2016).

44. I. Johnson and H. Liu, PLoS ONE 8, e65603 (2013).

45. N.A. Agha, F. Feyerabend, B. Mihailova, S. Heidrich, U. Bismayer, and R. Willumeit-Römer, Mater. Sci. Eng. C 58, 817 (2016).

46. S.V. Lamaka, J. Gonzalez, D. Mei, F. Feyerabend, R. Willumeit-Römer, and M.L. Zheludkevich, Adv. Mater. Interfaces 5 (18), 1800169 (2018).

47. J. Gray-Munro and M. Strong, J. Colloids Interfaces Sci. 393, 421 (2013)

48. S. Höhn, S. Virtanen, and A.R. Boccaccini, Appl. Surf. Sci. $464,212(2019)$

49. R. Hou, R. Willumeit-Römer, V.M. Garamus, M. Frant, J. Koll, F. Feyerabend, and A.C.S. Appl, Mater. Interfaces 10, 42175 (2018).

50. R. Willumeit, J. Fischer, F. Feyerabend, N. Hort, U. Bismayer, S. Heidrich, and B. Mihailova, Acta Biomater. 7, 2704 (2011).

51. R. Willumeit-Römer, N. Ahmad Agha, and B. Luthringer, Degradable Magnesium Implants-Assessment of the Current Situation.Magnesium Technology 2018. TMS 2018, ed. D. Orlov, V. Joshi, K. Solanki, and N. Neelameggham (Cham: Springer, 2018), p. 405.

52. N.A. Agha, R. Willumeit-Römer, D. Laipple, B. Luthringer, and F. Feyerabend, PLoS ONE 11, e0157874 (2016).

53. W. Ng, K. Chiu, and F. Cheng, Mater. Sci. Eng. C 30, 898 (2010).

54. L. Wu, B.J. Luthringer, F. Feyerabend, A.F. Schilling, and R. Willumeit, Acta Biomater. 10, 2843 (2014).

55. L. Wu, F. Feyerabend, A.F. Schilling, R. Willumeit-Römer, and B.J. Luthringer, Acta Biomater. 27, 294 (2015).

56. H. Oknin, D. Steinberg, and M. Shemesh, Front. Microbiol. 6, 907 (2015).

57. D. Tie, R. Guan, H. Liu, A. Cipriano, Y. Liu, Q. Wang, Y. Huang, and N. Hort, Acta Biomater. 29, 455 (2016).

58. S. Zaatreh, D. Haffner, M. Strauß, K. Wegner, M. Warkentin, C. Lurtz, C. Zamponi, W. Mittelmeier, B. Kreikemeyer, and R. Willumeit-Römer, Biofouling 33, 294 (2017).

59. M.I. Rahim, M. Rohde, B. Rais, J.M. Seitz, and P.P. Mueller, J. Biomed. Mater. Res. Part A 104, 1489 (2016).

60. Y. Koo, Y. Jang, and Y. Yun, Mater. Sci. Eng. B 219, 45 (2017).

61. K. Törne, A. Örnberg, and J. Weissenrieder, Acta Biomater. 48,541 (2017).

62. Y. Zhang, J. Li, and J. Li, J. Mech. Behav. Biomed. Mater. 80, 246 (2018).

63. Y. Jang, B. Collins, J. Sankar, and Y. Yun, Acta Biomater. 9, 8761 (2013).

64. J. Zhang, H. Li, W. Wang, H. Huang, J. Pei, H. Qu, G. Yuan, and Y. Li, Acta Biomater. 69, 372 (2018).

65. M. Badar, H. Lünsdorf, F. Evertz, M.I. Rahim, B. Glasmacher, H. Hauser, and P.P. Mueller, Acta Biomater. 9, 7580 (2013). 
66. S.A. Luffy, D.T. Chou, J. Waterman, P.D. Wearden, P.N. Kumta, and T.W. Gilbert, J. Biomed. Mater. Res. Part A 102, 611 (2014).

67. M. Bornapour, H. Mahjoubi, H. Vali, D. Shum-Tim, M. Cerruti, and M. Pekguleryuz, Mater. Sci. Eng. C 67, 72 (2016).

68. J.-W. Lee, H.-S. Han, K.-J. Han, J. Park, H. Jeon, M.-R. Ok, H.-K. Seok, J.-P. Ahn, K.E. Lee, and D.-H. Lee, PNAS 113, 716 (2016).

69. N. Grün, P. Holweg, S. Tangl, J. Eichler, L. Berger, J. van den Beucken, J. Löffler, T. Klestil, and A. Weinberg, Acto Biomater. 78, 378 (2018).

70. D. Bian, J. Deng, N. Li, X. Chu, Y. Liu, W. Li, H. Cai, P. Xiu, Y. Zhang, Z. Guan, and A.C.S. Appl, Mater. Interfaces 10, 4394 (2018).

71. J. Moosmann, B. Zeller-Plumhoff, D.C.F. Wieland, S. Galli, D. Krüger, T. Dose, H. Burmester, F. Wilde, M. Bech, N. Peruzzi, B. Wiese, A. Hipp, F. Beckmann, J. Hammel and R. Willumeit-Römer, Biodegradable magnesium-based implants in bone studied by synchrotron radiation microtomography, in SPIE Optical Engineering + Applications: Developments in X-Ray Tomography XI, (10391, International Society for Optics and Photonics, 2017), p. 1039100.

72. R. Willumeit-Römer, J. Moosmann, B. Zeller-Plumhoff, D.F Wieland, D. Krüger, B. Wiese, A. Wennerberg, N. Peruzzi, S. Galli and F. Beckmann, Visualization of implant failure by synchrotron tomography, in TMS Annual Meeting \& Exhibition, (Springer, 2018), p. 275.

73. T.A. Grünewald, A. Ogier, J. Akbarzadeh, M. Meischel, H. Peterlik, S. Stanzl-Tschegg, J.F. Löffler, A.M. Weinberg, and H.C. Lichtenegger, Acta Biomater. 31, 448 (2016).

74. M.I. Rahim, A. Weizbauer, F. Evertz, A. Hoffmann, M. Rohde, B. Glasmacher, H. Windhagen, G. Gross, J.M. Seitz, and P.P. Mueller, J. Biomed. Mater. Res. Part A 105, 697 (2017).

75. L. Tan, Q. Wang, X. Lin, P. Wan, G. Zhang, Q. Zhang, and K. Yang, Acta Biomater. 10, 2333 (2014).

76. T. Grünewald, H. Rennhofer, B. Hesse, M. Burghammer, S. Stanzl-Tschegg, M. Cotte, J. Löffler, A. Weinberg, and H. Lichtenegger, Biomaterials 76, 250 (2016).

77. J. Draxler, E. Martinelli, A.M. Weinberg, A. Zitek, J. Irrgeher, M. Meischel, S.E. Stanzl-Tschegg, B. Mingler, and T. Prohaska, Acta Biomater. 51, 526 (2017).

78. F. Amerstorfer, S.F. Fischerauer, L. Fischer, J. Eichler, J. Draxler, A. Zitek, M. Meischel, E. Martinelli, T. Kraus, and S. Hann, Acta Biomater. 42, 440 (2016).

Publisher's Note Springer Nature remains neutral with regard to jurisdictional claims in published maps and institutional affiliations. 